\title{
Prediction of Low-Voltage Tetrafluoromethane Emissions Based on the Operating Conditions of an Aluminium Electrolysis Cell
}

\author{
LUKAS DION @ị, ${ }^{1,3}$ LÁSZLÓ I. KISS, ${ }^{1}$ SÁNDOR PONCSÁK, ${ }^{1}$ \\ and CHARLES-LUC LAGACÉ ${ }^{2}$ \\ 1.-Université du Québec à Chicoutimi, 555 boulevard de l'Université, Chicoutimi, QC G7H 2B1, \\ Canada. 2.-Aluminerie Alouette Inc., 400 chemin de la Pointe-Noire, C.P. 1650, Sept-Îles, \\ QC G4R 5M9, Canada. 3.-e-mail: lukas.dion@uqac.ca
}

Greenhouse gas (GHG) generation is inherent in the production of aluminium by a technology that uses carbon anodes. Most of those GHG are composed of $\mathrm{CO}_{2}$ produced by redox reaction that occurs in the cell. However, a significant fraction of the annual GHG production is composed of perfluorocarbons (PFC) resulting from anode effects (AE). Multiple investigations have shown that tetrafluoromethane $\left(\mathrm{CF}_{4}\right)$ can be generated under low-voltage conditions in the electrolysis cells, without global anode effect. The aim of this paper is to find a quantitative relationship between monitored cell parameters and the emissions of $\mathrm{CF}_{4}$. To achieve this goal, a predictive algorithm has been developed using seven cell indicators. These indicators are based on the cell voltage, the noise level and other parameters calculated from individual anode current monitoring. The predictive algorithm is structured into three different steps. The first two steps give qualitative information while the third one quantitatively describes the expected $\mathrm{CF}_{4}$ concentration at the duct end of the electrolysis cells. Validations after each step are presented and discussed. Finally, a sensitivity analysis was performed to understand the effect of each indicator on the onset of low-voltage PFC emissions. The standard deviation of individual anode currents was found to be the dominant variable. Cell voltage, noise level, and maximum individual anode current also showed a significant correlation with the presence of $\mathrm{CF}_{4}$ in the output gas of an electrolysis cell.

\section{INTRODUCTION}

In primary aluminium reduction, continuous efforts are taken by the industry to minimize the tonnes of $\mathrm{CO}_{2}$ equivalent produced per ton of aluminium. Perfluorocarbon (PFC) emissions, composed essentially of tetrafluoromethane $\left(\mathrm{CF}_{4}\right)$ and hexafluoroethane $\left(\mathrm{C}_{2} \mathrm{~F}_{6}\right)$ are key elements to consider in this process. The global warming potential of these two gases is 6630 and 11,100 times greater than $\mathrm{CO}_{2}$, respectively. ${ }^{1}$ They are generated during an undesired event in the cell called an anode effect. This event is usually associated with an important increase in the cell voltage and is easily identifiable. Hence, these 'high-voltage PFC' emissions are well known in the industry and specific guidelines ${ }^{2}$ exist to quantify the amount of gas generated during this event. For this reason, smelters have optimised their process worldwide over the years and the total amount of PFC emissions from the aluminium industry has been significantly reduced between 1990 and $2010 .^{3}$ However, by lowering the AE frequency and duration, another source of emissions has become more apparent in recent years, characterized as 'low-voltage PFC' emissions. This particular type of emission can occur for a significant period of time with little or no indication of misbehaviour in the electrolytic cell, for instance, an increase in cell the noise or voltage. For this reason, low-voltage PFC are important to take into consideration but, up to now, no available method other than real-time PFC monitoring exists to account for 
these emissions. ${ }^{4}$ This paper investigates the correlation between specific cell variables and the level of $\mathrm{CF}_{4}$ emissions at the duct end of the electrolysis cell.

\section{STATE OF THE ART}

Numerous authors (see Table I) have previously investigated the occurrence of low-voltage PFC. There is general agreement in the scientific community that the basic mechanisms generating lowvoltage PFC are similar to the standard AE mechanism, which is very well documented. AE occurs due to the privation of dissolved alumina in a localized region of the bath. If it happens, transport of the electric charges is no longer supported by the standard electrolysis Reaction 1 . This will lead to an increase in the anodic overvoltage, and subsequent Reactions 2-3 will occur in the cell, leading to the electrolysis of the cryolite and the generation of PFC; therefore, an AE. ${ }^{5}$

$$
\begin{gathered}
2 \mathrm{Al}_{2} \mathrm{O}_{3(\text { diss })}+3 \mathrm{C}_{(\mathrm{s})} \rightarrow 4 \mathrm{Al}_{(\mathrm{l})}+3 \mathrm{CO}_{2(\mathrm{~g})} \\
E^{0}=-1.18 \mathrm{~V} \\
4 \mathrm{Na}_{3} \mathrm{AlF}_{6(\mathrm{l})}+3 \mathrm{C}_{(\mathrm{s})} \rightarrow 4 \mathrm{Al}_{(\mathrm{l})}+3 \mathrm{CF}_{4(\mathrm{~g})}+12 \mathrm{NaF}_{(\text {diss })} \\
E^{0}=-2.58 \mathrm{~V} \\
2 \mathrm{Na}_{3} \mathrm{AlF}_{6(\mathrm{l})}+2 \mathrm{C}_{(\mathrm{s})} \rightarrow 2 \mathrm{Al}_{(\mathrm{l})}+\mathrm{C}_{2} \mathrm{~F}_{6(\mathrm{~g})}+6 \mathrm{NaF}_{(\text {diss })} \\
E^{0}=-2.80 \mathrm{~V}
\end{gathered}
$$

Once an $\mathrm{AE}$ occurs in the cell, the localised area where PFC are produced usually becomes strongly resistive to the passage of current (increase in ohmic resistance) and the current will be redistributed toward the other anodes in the cell. This redistribution generally provokes the same problem elsewhere and the $\mathrm{AE}$ propagates from one anode to the other until terminated, meanwhile significantly increasing the global cell voltage. The detection limit of an $\mathrm{AE}$ varies from one smelter to another. However, a generally accepted value is when the cell voltage exceeds $8 \mathrm{~V} .^{6}$ For this reason, generalized AE, or high-voltage anode effects (HVAE), are easily identifiable and are very well documented in the literature. ${ }^{6-8}$

However, if the $\mathrm{AE}$ phenomenon occurs only locally in the cell without propagating to all the other anodes, it can lead to a continuous generation of PFC while the cell voltage still remains under the $\mathrm{AE}$ detection limit. This makes the detection of lowvoltage emissions difficult without continuous monitoring of the output gas composition. This event can either self-terminate due to alumina or current redistribution or, eventually, it can lead to a HVAE. Historically, this phenomenon was called "background or non-AE PFC emissions". Recently, the International Aluminum Institute (IAI) has adopted the term "low-voltage AE" (LVAE). ${ }^{9}$ This paper will use the latest terminology.

Some authors ${ }^{10-14}$ refer to Reactions $4-6$ as the dominant mechanism for the generation of PFC under low-voltage conditions as these reactions can occur without a significant increase in the anodic overvoltage. Furthermore, it could also explain why most of the LVAE measurements only indicate very small traces of $\mathrm{C}_{2} \mathrm{~F}_{6}$ above the detection limit of the instrument. In contrast, during HVAE, the ratio of $\mathrm{C}_{2} \mathrm{~F}_{6}$ to $\mathrm{CF}_{4}$ can change with time and cell technologies but the typical value is approximately 0.1 .

$$
\begin{aligned}
& 2 \mathrm{AlF}_{3(\text { diss })}+\mathrm{Al}_{2} \mathrm{O}_{3(\text { diss })}+3 \mathrm{C}_{(\mathrm{s})} \rightarrow 4 \mathrm{Al}_{(\mathrm{l})}+3 \mathrm{COF}_{2(\mathrm{~g})} \\
& E^{0}=-1.88 \mathrm{~V}
\end{aligned}
$$

$$
\begin{aligned}
& 2 \mathrm{COF}_{2(\mathrm{~g})}+\mathrm{C}_{(\mathrm{s})} \rightarrow 2 \mathrm{CO}_{(\mathrm{g})}+\mathrm{CF}_{4(\mathrm{~g})} \\
& K=94.8 \\
& 3 \mathrm{COF}_{2(\mathrm{~g})}+2 \mathrm{C}_{(\mathrm{s})} \rightarrow 3 \mathrm{CO}_{(\mathrm{g})}+\mathrm{C}_{2} \mathrm{~F}_{6(\mathrm{~g})} \\
& \quad K=1.2 \times 10^{-3}
\end{aligned}
$$

Past researchers have demonstrated that multiple parameters or events could be linked to the occurrence of low-voltage PFC emissions. Their conclusions are summarized in Table I and the most relevant points are discussed briefly afterward.

Most authors ${ }^{5,7,10-12,16-19}$ agree that alumina concentration, anode current density and anodic overvoltage have a significant impact on the onset of low-voltage PFC emissions. All of these parameters are interrelated and will dictate if the localised overvoltage eventually exceeds the threshold necessary to generate PFC. Similarly, LVAE related to the feeding strategy have been observed at the end of underfeeding periods. This observation confirms that low alumina concentration in the bath is more likely to generate $\mathrm{CF}_{4}$ even during normal cell operation.

Some authors ${ }^{11,12,15,16}$ have explored the influence of bath temperature, bath chemistry and superheat on the PFC generation. These variables will have an influence on the maximum solubility of the alumina in the bath as well as on the kinetics of its dissolution. Hence, keeping these variables in an appropriate range will minimize the alumina concentration gradients in the electrolytic bath.

The new, high-amperage cells that are becoming more prevalent in the aluminium industry are composed of a greater number of anodes with larger surface areas in order to preserve anode current density. For this reason, a local AE is less likely to propagate towards the other anodes and thus probably can last longer. ${ }^{7}$ Moreover, as each anode are connected in parallel electrically, the effect of 


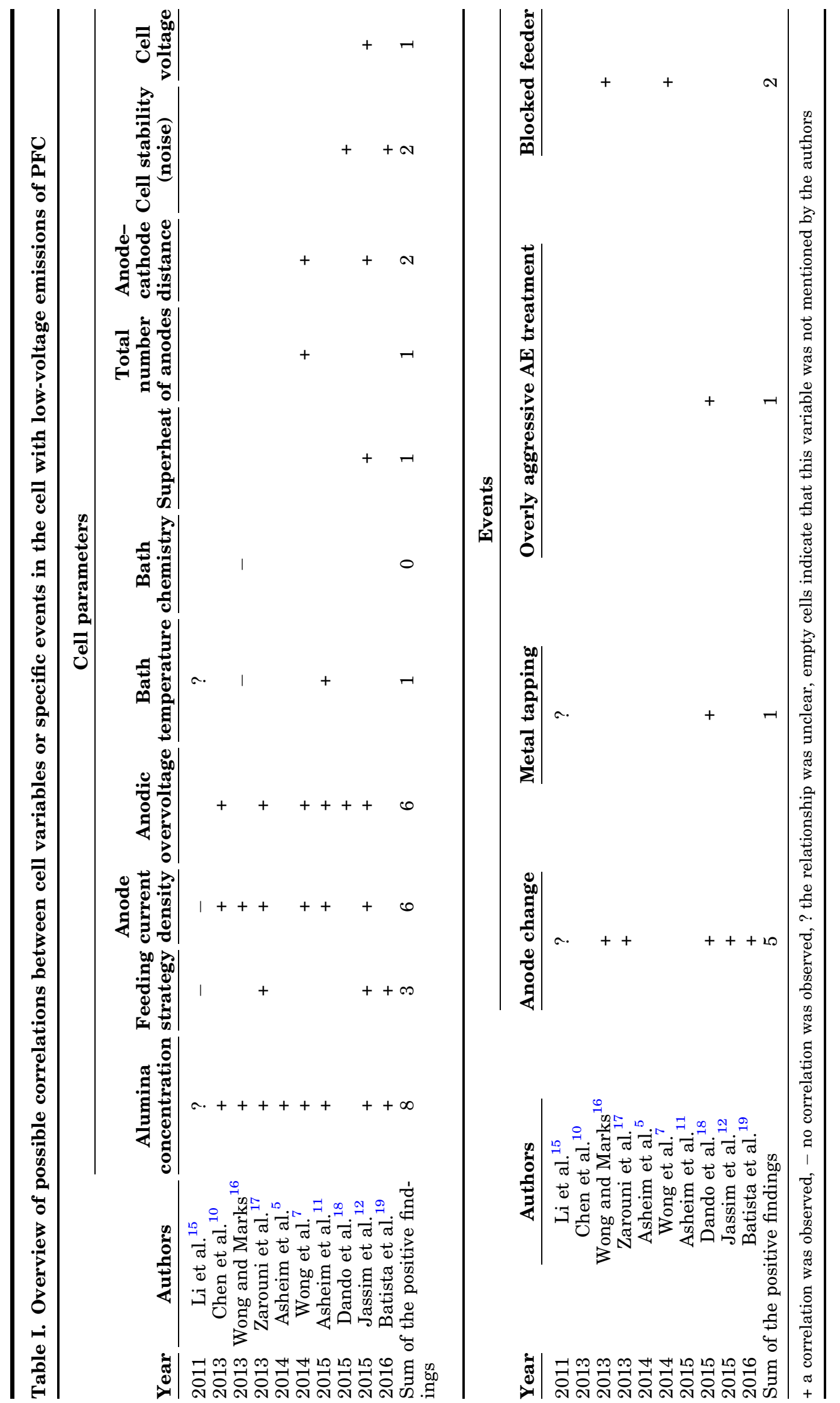


gas passivation under a single anode will be less significant on the global cell voltage if the total number of anodes increases.

PFC emissions are frequently observed up to multiple hours after an anode change. ${ }^{12,16-19}$ This is due to the redistribution of current towards anodes that increases the current density locally. The nonuniformity of the current distribution can be amplified if the anode-cathode distance is reduced in order to operate with lower energy consumption. In such a cell, a small imbalance in the anode setting will have a greater impact on the anode current distribution, thus increasing the risk of generating PFC.

\section{EXPERIMENTAL SETUP}

Data used in this study were collected during two measurement campaigns of gas emissions at Aluminerie Alouette from prebaked AP40LE cells using point feeders and operating above $390 \mathrm{kA}$. They were equipped with on-line monitoring of individual anode currents using a measurement frequency of $1 \mathrm{~Hz}$. Cell current, voltage and pseudo-resistance were measured by the cell control system with the same frequency, and all the data were recorded. Therefore, only one cell at a time was monitored, and there was no dilution other than the gases entering the cell through the hooding. Inspection of the hooding was performed frequently to make sure it remained in similar condition throughout the whole campaign.

During these periods, gas composition was measured with a GASMET ${ }^{\mathrm{TM}}$ DX-4000 Fourier transformed infrared spectrometer (FTIR) using a Peltier cooled mercury-cadmium-telluride detector (sample cell path: $9.8 \mathrm{~m}$, volume: $0.5 \mathrm{~L}$, resolution: $7.8 \mathrm{~cm}^{-1}$ ). A stainless steel sampling probe was located at the duct end of the electrolysis cell and gas was continuously fed to the analyzer at a volumetric rate of $2.5 \mathrm{~L} \mathrm{~min}^{-1}$. The gas stream was sent sequentially through a $15-\mu$ filter, a desiccant, activated alumina, a 5- $\mu$ filter and finally a $2-\mu$ filter to remove dust, traces of water and hydrogen fluoride for the protection of the measuring equipment. The gas went through a line heated at $120^{\circ} \mathrm{C}$ before entering the FTIR and concentration measurements were performed at a rate of 10 scans per second. Average values for 5-s periods were recorded. The background spectrum was redefined using high purity nitrogen every $24 \mathrm{~h}$.

Gas composition was measured for a total of 2 weeks. The collected data were then classified into 15 scenarios. Thirteen of them were selected because the $\mathrm{CF}_{4}$ concentration remained within the range of interest for a significantly long period. Two extra scenarios represent stable periods without LVAE. $\mathrm{CF}_{4}$ emissions issued from HVAE were not considered in this study. Additional information on the preparation of the data has been published previously. ${ }^{20}$ After the data selecting process, 22,000 data points remained. Half of them corresponded to LVAE. This relatively high number of points was sufficient to develop the six artificial neural networks required for the predictive algorithm described below, but a further increase in the total number of data points could still improve its performance.

\section{DEVELOPMENT OF THE PREDICTIVE ALGORITHM}

A predictive algorithm was developed to predict the $\mathrm{CF}_{4}$ concentration at the duct end of an electrolysis cell using continuously measured parameters. The range of interest of the $\mathrm{CF}_{4}$ concentration for this study is between $10 \mathrm{ppb}$ and $2000 \mathrm{ppb}$. The lower limit was set according to the threshold detection of the FTIR, and the upper limit was determined by the highest $\mathrm{CF}_{4}$ concentration that was measured under LVAE conditions. $\mathrm{C}_{2} \mathrm{~F}_{6}$ was not considered as most of the data remained under the detection limit of the FTIR (20 ppb).

The strategy of the algorithm, as well as the choice of the input variables, was developed iteratively. Multiple combinations have been examined including different strategies and/or different inputs. It is important to mention that further refinement is still possible but it would first require additional measurement campaigns.

Seventy percent of the selected data were used for the learning process to develop the artificial neural networks and the remaining 30\% was used for validation to evaluate the accuracy of the predictions. One of the main applications of this algorithm is the sensitivity analysis that has been performed subsequentially. This analysis clearly indicates the variables with the strongest influence on the emissions of LVAE as well as the expected variations over the entire range of each entry variable.

Artificial neural networks (ANN) behind the algorithm were developed using the data mining package offered with STATISTICA $12^{\circledR}$.

\section{List of Indicators}

The first selection of the potential indicators (input variables) was based on the results of the literature review indicating which parameters were most likely to correlate with the presence of low-voltage $\mathrm{CF}_{4}$ emissions. To introduce an input to the algorithm, it was necessary to have data collected with relatively high frequency $(0.2-1 \mathrm{~Hz})$ for each respective input. As alumina concentration could only be measured intermittently, it was not included as an input. After optimisation, seven variables were retained as inputs for the predictive model. Most of these are related to individual current monitoring as it offers local data on the cell behaviour. More importantly, it supplies indirect information regarding the alumina distribution $^{21}$ and the influence of changing anodes. The list of the seven indicators:

- Cell voltage (volts) Average cell voltage computed for 5 consecutive seconds. 


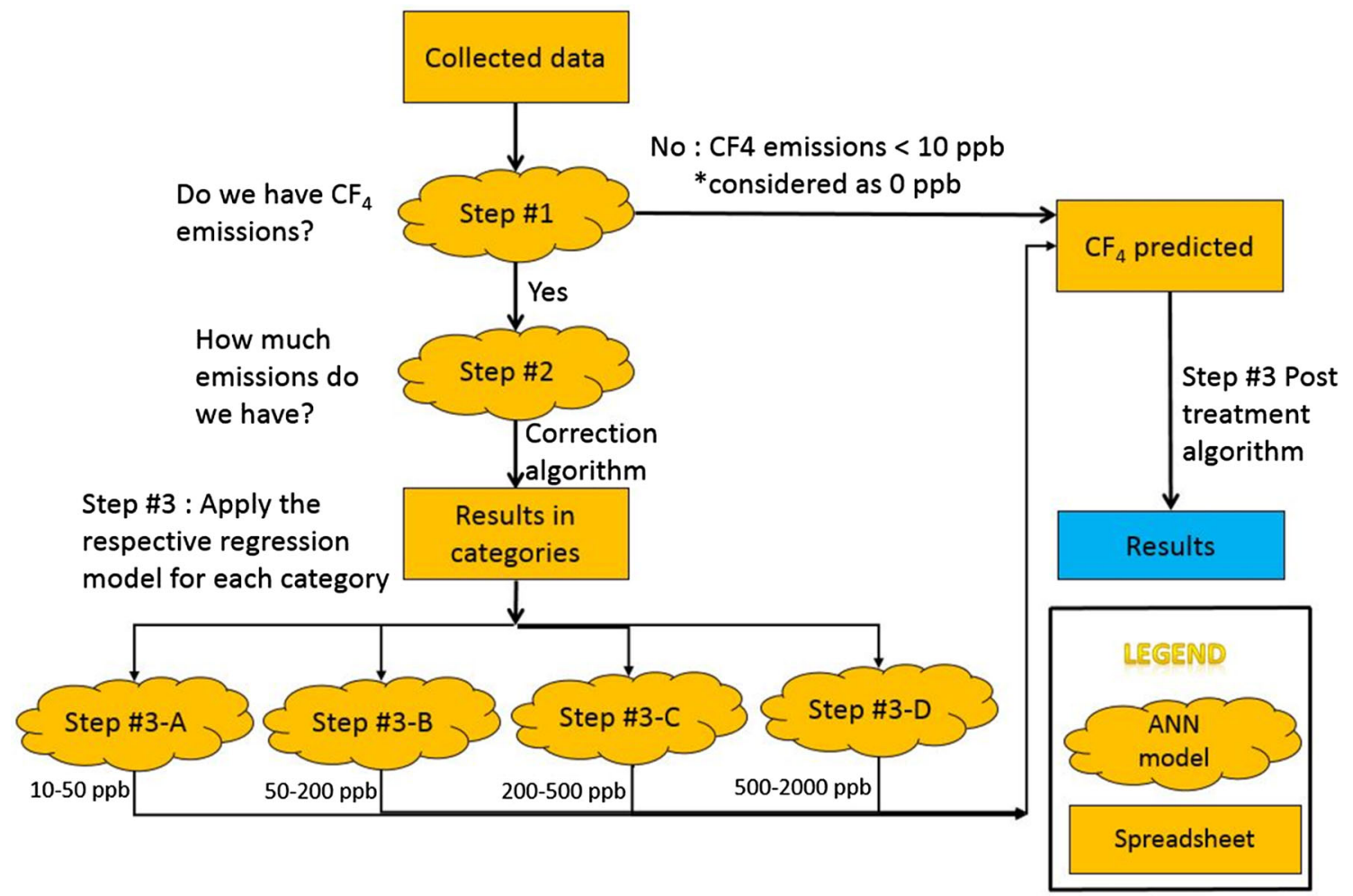

Fig. 1. The predictive algorithm strategy.

- Noise (temporal stability) indicator (nanoohms) The difference between the maximum and the minimum pseudo-resistance measured for the cell within the last $6 \mathrm{~s}$.

- Maximum current driven through individual anodes (amps) The highest current value that has been observed among the individual anodes.

- Standard deviation between individual anode currents (amps) For every second, the standard deviation was calculated using individual anode current measurements from the entire cell.

- Absolute difference between upstream and downstream current averages (amps) the average current value is calculated for both halves of the cell and the absolute difference between the two sides is calculated.

- Absolute difference between tap hole and duct end side current averages (amps) Same as the previous variable but the division of the cell was performed across the other axis.

- Range of measured individual currents (amps) Difference between the maximum and the minimum individual anode currents measured.

\section{Description of the Algorithm Strategy}

The algorithm is divided into three steps as shown in Fig. 1. The first step is performed by an ANN designed to indicate if the conditions are met for the generation of $\mathrm{CF}_{4}$ in the electrolysis cell. The output from this ANN can either be positive or negative. A positive output indicates that $\mathrm{CF}_{4}$ emission is expected at the duct end of the electrolysis cell under those conditions. In contrast, a negative output indicates that the measured $\mathrm{CF}_{4}$ concentration would be below the limit of detection. Negative outputs are considered as $0 \mathrm{ppb}$ concentration. During the learning phase of the ANN, it was necessary to use weighting factors to favor the predictions of "no emissions". This minimizes the risk of amplifying the error caused by a wrong prediction in the following steps, which could lead to divergent predictions. Therefore, weighting factors of $2: 1$ were used in favor of the negative predictions.

The second step of the algorithm is performed by another ANN that aims to classify its output in specific concentration ranges that are to be expected without assigning a quantitative value. A correction algorithm is applied after this ANN to minimise the risk of wrong classification. This correction considers the previous temporal prediction to assure consistency. The resulting output can be divided into four different categories:
A. $\quad 10 \mathrm{ppb}-49.99 \mathrm{ppb}$
B. $50 \mathrm{ppb}-199.99 \mathrm{ppb}$
C. $200 \mathrm{ppb}-499.99 \mathrm{ppb}$
D. $500 \mathrm{ppb}-2000 \mathrm{ppb}$

The last step of the algorithm assigns a quantitative $\mathrm{CF}_{4}$ concentration to the specific entry conditions. It uses four artificial networks working in parallel 

of an Aluminium Electrolysis Cell
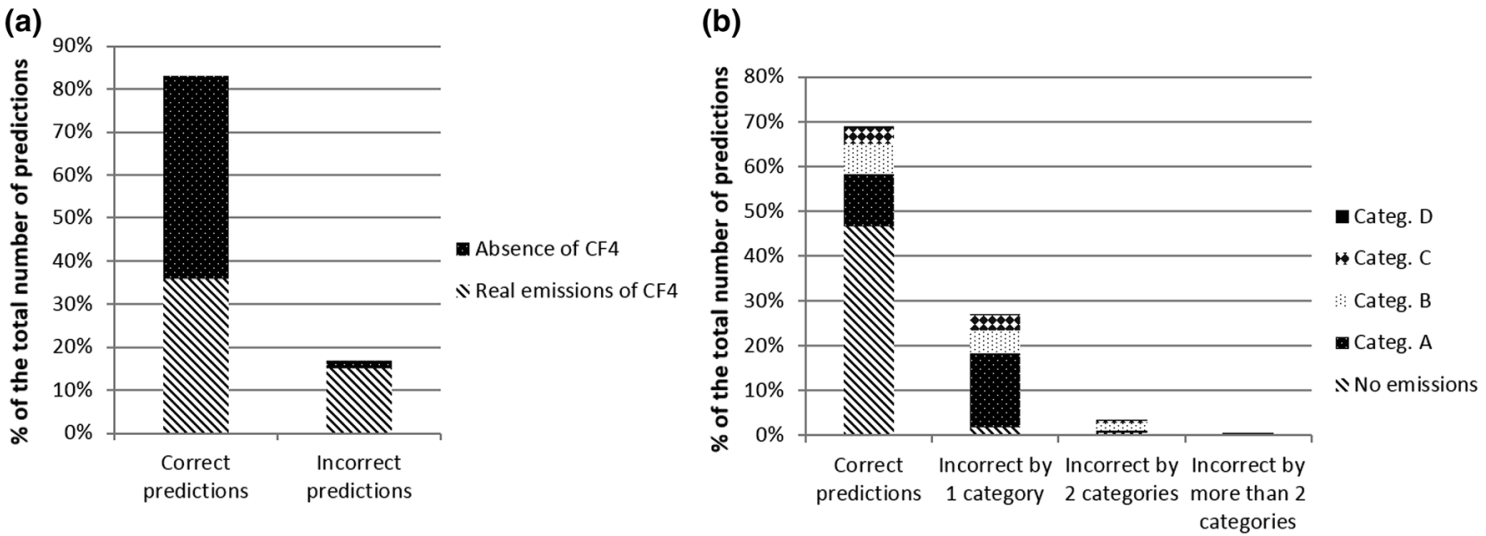

Fig. 2. (a) Percentages of correct and incorrect predictions after Step \#1. (b) Percentages of correct predictions along with the different offsets in incorrect predictions after Step \#2.

depending on the respective category that was assigned in the previous steps. Once each value has been defined, a post-treatment is applied to the prediction to take into account the evolution of the $\mathrm{CF}_{4}$ concentration over time. In this case, the posttreatment is a mobile moving average over a 5-min period.

\section{RESULTS AND DISCUSSION}

\section{Validation of the Algorithm}

Thirty percent of the collected data was used exclusively for the validation of the model. These data were fed into the model and the results were examined after each step of the algorithm to evaluate its performance.

Figure 2a clearly indicates the ability of the model to predict the presence or absence of $\mathrm{CF}_{4}$ based on the input variables. The percentage of correct predictions after step \#1 rises above $83 \%$. Moreover, the effect of the weights discussed previously is clearly visible in the incorrect predictions column. Hence, when no $\mathrm{CF}_{4}$ is present in the output gas composition, the model rarely predicts otherwise, which increases the performance in the following steps of the algorithm. Figure $2 \mathrm{~b}$ indicates that $69 \%$ of the data is correctly classified after the second step. The results indicate that most incorrect predictions are offset only by 1 category. Further investigation revealed that the majority of incorrect classifications are due to concentrations that are near the limits of each category (i.e. $10 \mathrm{ppb}, 50 \mathrm{ppb}$, $200 \mathrm{ppb}$ and $500 \mathrm{ppb}$ ). This is more important for classifications from the category $\mathrm{A}$, where the percentage of misclassifications exceeds the number of correct predictions. However, more than $80 \%$ of these incorrect predictions were within the range of $10 \mathrm{ppb}-15 \mathrm{ppb}$. Therefore, it might be relevant to reconsider the lower limit of prediction of the model in the future to avoid being too close to the detection limit of the FTIR. For this reason, it is unclear whether the errors came from the noise of the FTIR or if the variations within cell variables are just too small in this range of concentration to be detected above the normal noise level of each respective variable.

Final validation was performed by calculating the overall mass of $\mathrm{CF}_{4}$ emitted during each specific period based on the measurements and comparing it to the overall mass obtained using the predicted values for the same periods. The mass of $\mathrm{CF}_{4}$ was calculated using integration according to the trapezoid rule for each respective scenario and by multiplying the resulting $\left(\mathrm{ppb}^{*} \mathrm{~s}\right)$ by the flow rate at the duct end of the cell as well as by the $\mathrm{CF}_{4}$ density for the corresponding temperature and pressure. Illustrative results for all scenarios are presented in Fig. 3.

In most cases, the overall behaviour of the $\mathrm{CF}_{4}$ prediction is in good accordance with the corresponding measurements, including the cases where no emissions are present (Fig. 3-14 and 15). It indicates the consistent behaviour of the algorithm to quantitatively predict the concentration of $\mathrm{CF}_{4}$ from an electrolysis cell based exclusively on some of the cell parameters. The results in Fig. 4 are also consistent with this statement as they indicate that the model correctly predicts the total mass of $\mathrm{CF}_{4}$ within a $\pm 25 \%$ error margin in two-thirds of the cases. If we consider that to our knowledge, no other predictive model to account for low-voltage PFC emissions has been developed in the open literature, added to the fact that the average error for the entire set of data is $8 \%$, the algorithm's performance can be considered as good. Henceforth, it is possible to proceed with a sensitivity analysis representative of the inputs' effect.

\section{Sensitivity Analysis: Individual Effect of the Indicators on the Low-Voltage Emissions of $\mathbf{C F}_{4}$}

A sensitivity analysis was performed based on a seven-level full factorial design ${ }^{22}$ including all the seven indicators. Henceforth, it was possible to 

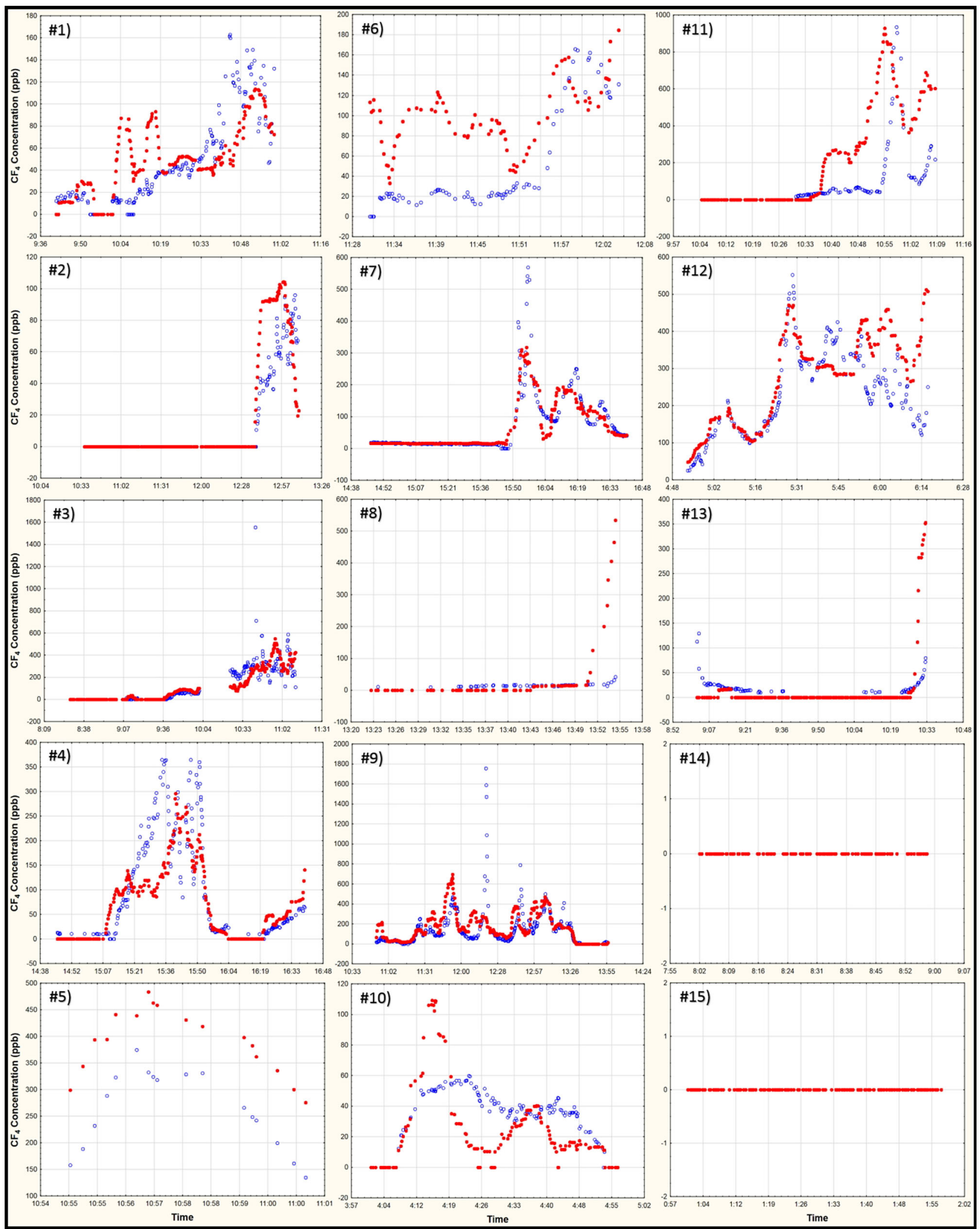

Fig. 3. Comparison between predicted $\mathrm{CF}_{4}$ concentrations (filled circles) and measured concentration (open circles). 


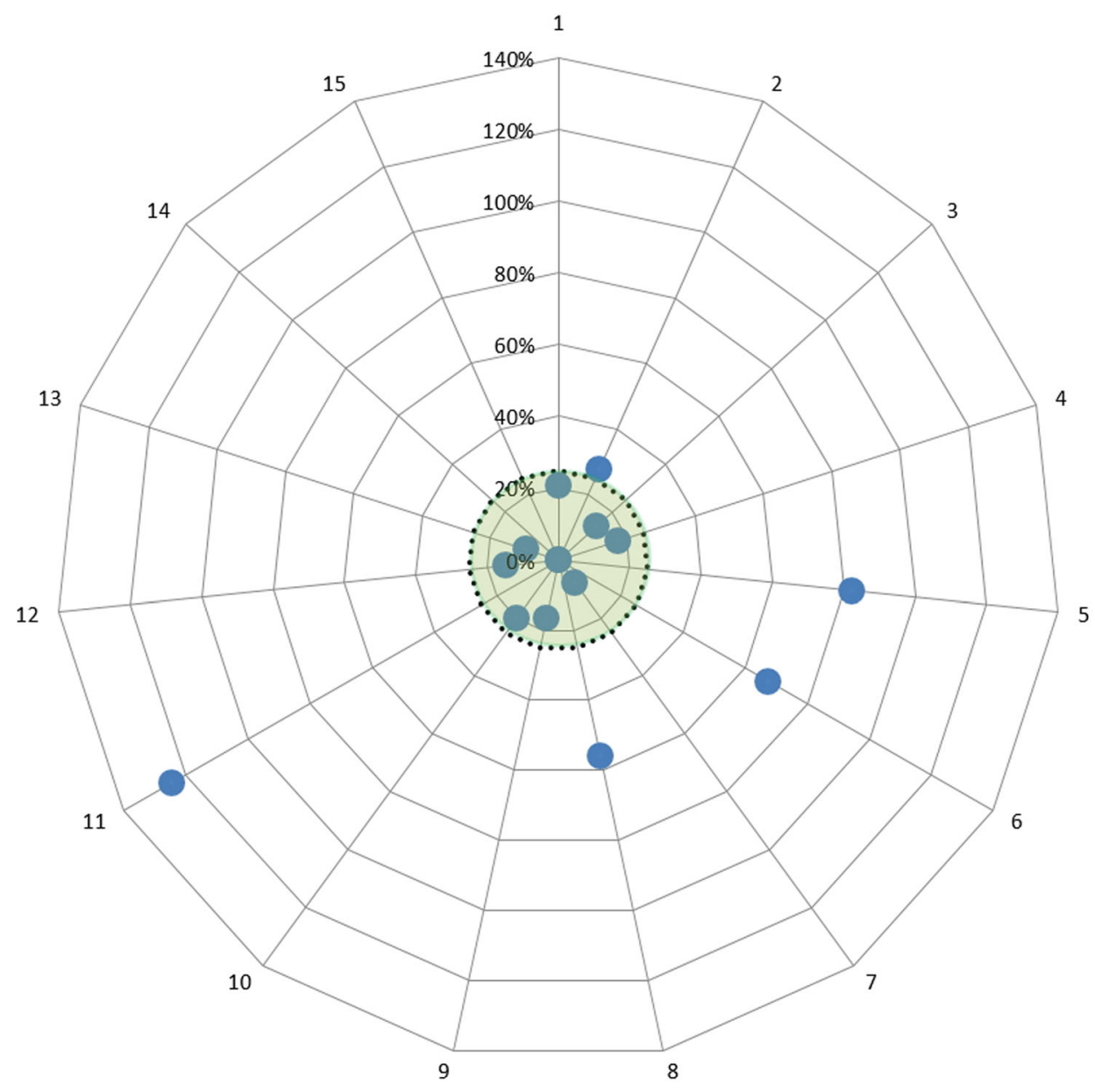

Absolute value of the error for each scenario $\cdots .$. Target area $( \pm 25 \%)$

Fig. 4. Radar chart illustrating the absolute value of the error percentages for all 15 scenarios.

examine the effect of each input variables on the resulting predictions obtained with the algorithm. For the purpose of identifying the dominant input variables, most of the useful information is available after the first step of the algorithm. Therefore, only these results are presented, as they are more relevant.

The exploration limits of each variable were defined using their respective data distribution collected during the measurement campaign. The corresponding lower and upper limits for each variable were defined as the 1st and the 99th centiles in order to eliminate the atypical values. The impact of the cross-effects between the different parameters was investigated but no significant interaction was observed, hence it is not presented in this study.

An investigation regarding the probability of $\mathrm{CF}_{4}$ emissions as a function of cell parameters was performed. For each individual variable, the total number of predicted emissions has been normalized for easier interpretation. The reference $(0 \%)$ indicates the point where the variable has no influence.
Hence, a positive value indicates that the presence of $\mathrm{CF}_{4}$ is more likely. In contrast, a negative value indicates that $\mathrm{CF}_{4}$ emission is predicted by the model less frequently. Moreover, a threshold value has been added to each figure. This threshold is based on the actual measurements and represents the transition point where the probability of occurrence of $\mathrm{CF}_{4}$ emissions gets higher than the probability of having no emissions. Figure 5 illustrates the change in $\mathrm{CF}_{4}$ emissions with respect to each input variable resulting from the sensitivity analysis. A clear correlation can be observed between a variable and the $\mathrm{CF}_{4}$ emissions if the slope is steep and the trend is uniform along most of the range studied.

A positive correlation was observed between an increasing cell voltage and the occurrence of $\mathrm{CF}_{4}$ emissions. It is important to consider that the voltage values from Fig. $5 \mathrm{a}$ are representative of a specific cell technology. However, the upper range of values can be representative of the variation that occurs after an anode change or when higher noise is observed in the pot. Interestingly, as the cell 

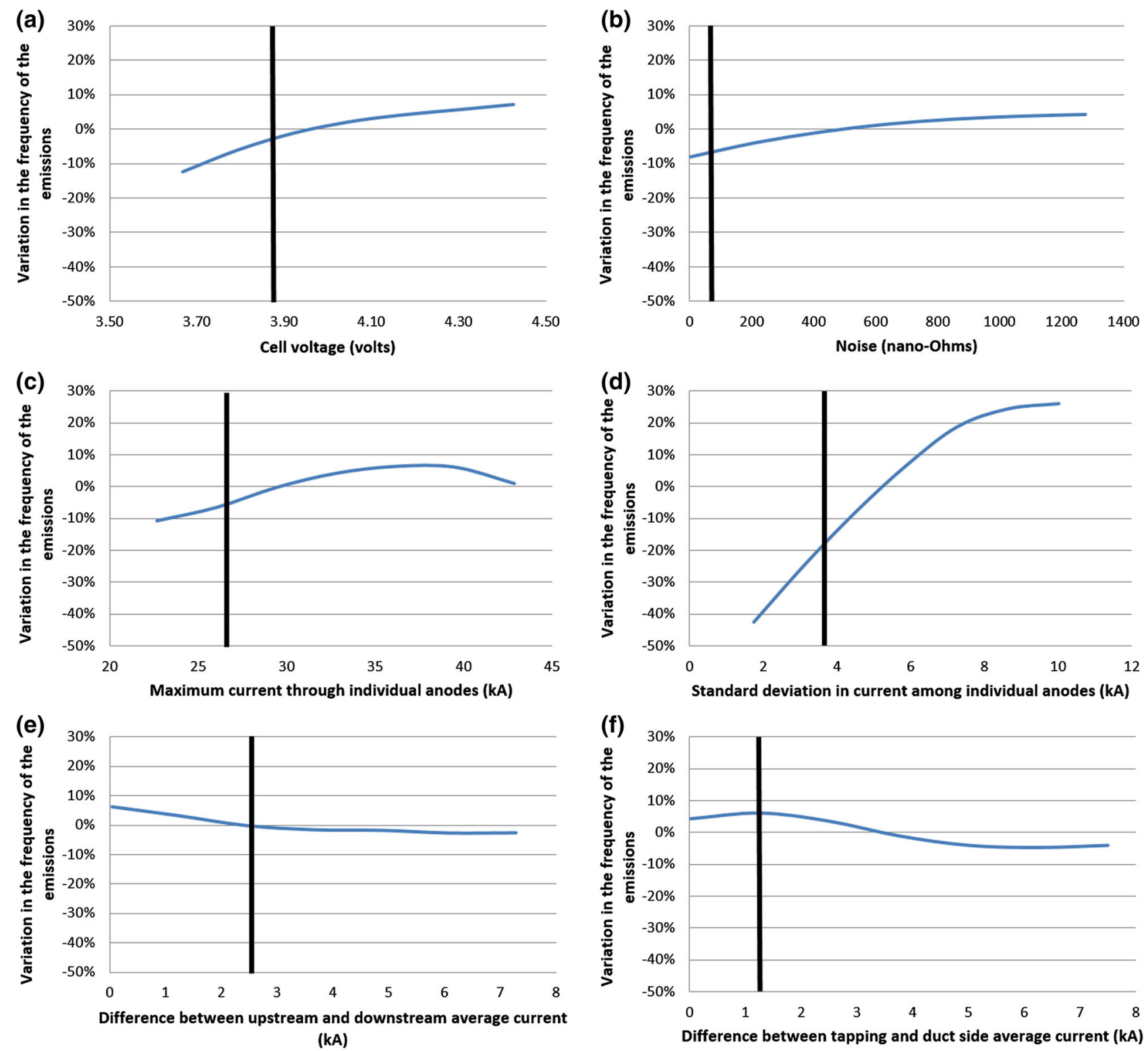
(kA)

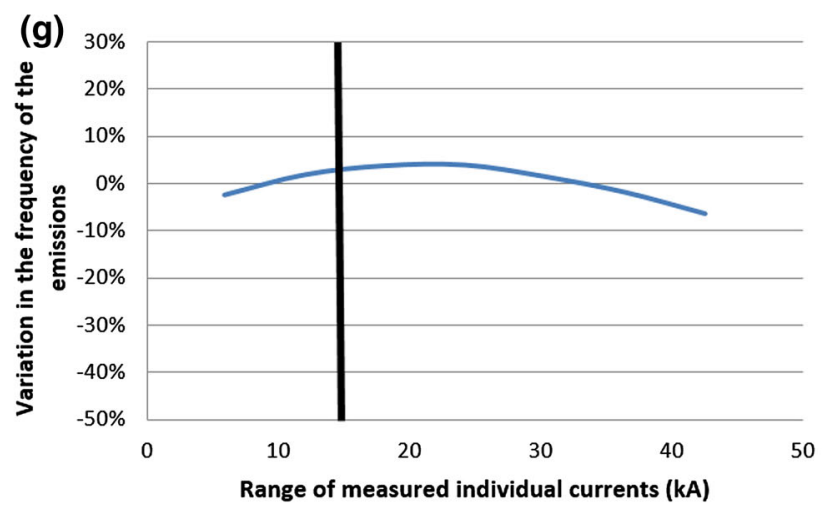

Fig. 5. Influence level of each indicator on the frequency of predictions of $\mathrm{CF}_{4}$ based on a full factorial design sensitivity analysis. The vertical line represents the measured threshold value for each variable. 
voltage decreases below the threshold value, the slope of influence is steeper. This indicates that variations in this range have a greater effect on $\mathrm{CF}_{4}$ emissions. It can be interpreted as a range of variation, which is more plausibly associated with an increase in overvoltage. In contrast, a higher increase in voltage is more likely associated with a change in the total resistance of the cell.

The noise level (Fig. 5b) has a positive correlation with the occurrence of $\mathrm{CF}_{4}$ emissions. However, an important variation in the stability of the cell will only generate a small increase in the probability of $\mathrm{CF}_{4}$ emissions.

The maximum current measured among the anodes (Fig. 5c) appears to have a positive influence on the generation of $\mathrm{CF}_{4}$ emissions up to $35 \mathrm{kA}$ $(\approx 1.75$ times the normal level). Up to a certain point, it can be representative of the current redistribution following an anode change or when excessive gas passivates the anodes. Consequently, higher current locally consumes the alumina more rapidly which eventually leads to $\mathrm{PFC}$ generation in that region of the cell. Further investigations are required to see if those conditions are maintained for the same anodes or if the current jumps from one anode to the another over time. Moreover, very high current in a single anode, maintained for a long period, can only be explained by a short-circuit generating other negative impacts for the cell. This phenomenon explains the drop in the $\mathrm{CF}_{4}$ occurrence when the maximum current in an anode reaches more than $40 \mathrm{kA}$.

The results from Fig. 5d indicate a clear and strong relationship between the standard deviation among individual anode currents and the prediction of $\mathrm{CF}_{4}$ emissions. These results are consistent with the literature as well as with the mechanism of PFC emissions. Therefore, when a disruption of the current uniformity starts generating LVAE, the local resistivity is expected to increase under specific anodes. It will lower the current from these anodes and redistribute a part of the current toward other anodes, hence amplifying the current non-uniformity in the cell. The behaviour appears to be linear up to a certain limit $(7.5 \mathrm{kA})$. Afterward, there is no more significant increase of the influence of this variable on the emissions of $\mathrm{CF}_{4}$.

Figure 5e shows a negative correlation but this effect is mainly due to a permanent offset of approximately $1.75 \mathrm{kA}$ between the average individual anode currents from the upstream and downstream side under normal operation. Henceforth, it has no real correlation with LVAE.

No significant correlation can be observed on Fig. $5 \mathrm{f}$ and $\mathrm{g}$ between the occurrence of $\mathrm{CF}_{4}$ emissions and those variables. However, even if these variables are not as useful in predicting the occurrence of LVAE, they are relevant in the subsequent steps of the algorithm to predict the level of these emissions when these are detected.

\section{CONCLUSION}

A study has been performed to determine whether certain measurable indicators permit the prediction of low-voltage PFC emissions from aluminum electrolysis cells. Inspired by a literature review and a good understanding of the mechanisms, seven indicators were selected and used to develop a predictive algorithm based on measurements carried out on selected aluminium electrolysis cells. The model is able to successfully predict the emissions of $\mathrm{CF}_{4}$ at the duct end of an electrolysis cell using only those seven inputs. A sensitivity analysis was performed using the algorithm to understand the effect of each variable on the occurrence of lowvoltage $\mathrm{CF}_{4}$ emissions.

The sensitivity analysis clearly demonstrated that inhomogeneity among individual anode currents is the best indicator to predict low-voltage $\mathrm{CF}_{4}$ emissions. Cell voltage and maximal anode current show also a significant and positive correlation with the emissions. The noise level has a positive, but not significant, correlation. No other measurable cell variable was found to have a direct and significant correlation with the occurrence of low-voltage PFC emissions.

The model described in this paper shows promising results as a predictive method, but further improvements are still required before it can be used as a robust quantitative tool integrated into the cell control system. Moreover, due to the variety of the reduction technologies and the limited accessibility of individual anode current monitoring across smelters worldwide, the proposed algorithm cannot be easily applied outside of the cell technology from which it was developed. However, the investigation and results described in this paper can lead to refinements that would be applicable throughout the entire aluminium industry.

Finally, the primary objective of this study was reached, namely, a new tool was developed, using certain key indicators to predict the generation of $\mathrm{CF}_{4}$ under low-voltage conditions.

\section{ACKNOWLEDGEMENTS}

This work was financed by a BMP-Innovation grant from a partnership composed of "Fonds de Recherche du Québec - Nature et Technologies" (FRQNT), "National Science and Engineering Research Council of Canada" (NSERC) and Aluminerie Alouette Inc. The authors would like to thank Aluminerie Alouette Inc. for the permission to present these results. The support and recommendations provided by Dr. Jerry Marks during the measuring campaign and in the interpretation of the results are acknowledged and greatly appreciated.

\section{OPEN ACCESS}

This article is distributed under the terms of the Creative Commons Attribution 4.0 International 
License (http://creativecommons.org/licenses/by/4.0/), which permits unrestricted use, distribution, and reproduction in any medium, provided you give appropriate credit to the original author(s) and the source, provide a link to the Creative Commons license, and indicate if changes were made.

\section{REFERENCES}

1. G. Myhre, D. Shindell, F.-M. Bréon, W. Collins, J. Fuglestvedt, J. Huang, D. Koch, J.-F. Lamarque, D. Lee, B. Mendoza, T. Nakajima, A. Robock, G. Stephens, T. Takemura, and $\mathrm{H}$. Zhang, Anthropogenic and natural radiative forcing. Climate Change 2013: The Physical Science Basis. Contribution of Working Group I to the Fifth Assessment Report of the Intergovernmental Panel on Climate Change, ed. T.F. Stocker, D. Qin, G.-K. Plattner, M. Tignor, S.K. Allen, J. Boschung, A. Nauels, Y. Xia, V. Bex, and P.M. Midgley (Cambridge, UK and New York, NY, USA: Cambridge University Press, 2013).

2. IPCC 2006, 2006 IPCC Guidelines for National Greenhouse Gas Inventories, Prepared by the National Greenhouse Gas Inventories Programme, H.S. Eggleston, L. Buendia, K. Miwa, T. Ngara, K. Tanabe (eds.) (Japan: IGES, 2006).

3. M. Fischedick, J. Roy, A. Abdel-Aziz, A. Acquaye, J.M. Allwood, J.-P. Ceron, Y. Geng, H. Kheshgi, A. Lanza, D. Perczyk, L. Price, E. Santalla, C. Sheinbaum, and K. Tanaka, Industry. Climate Change 2014: Mitigation of Climate Change. Contribution of Working Group III to the Fifth Assessment Report of the Intergovernmental Panel on Climate Change, ed. O. Edenhofer, R. Pichs-Madruga, Y. Sokona, E. Farahani, S. Kadner, K. Seyboth, A. Adler, I. Baum, S. Brunner, P. Eickemeier, B. Kriemann, J. Savolainen, S. Schlömer, C. von Stechow, T. Zwickel, and J.C. Minx (Cambridge, UK and New York, NY, USA: Cambridge University Press, 2014).

4. D.S. Wong, P. Fraser, P. Lavoie, and J. Kim, JOM 67, 342 (2015).

5. H. Asheim, T.A. Aarhaug, A. Ferber, O.S. Kjos, and G.M. Haarberg, Light Metals 2014, ed. J. Grandfield (Hoboken: Wiley, 2014), pp. 535-539.

6. A. Tabereaux (Paper presented at the Eight Australasian Aluminium Smelting Technology Conference and Workshops, Yeppoon, Australia, 2004).
7. D. Wong, A. Tabereaux, and P. Lavoie, Light Metals 2014, ed. J. Grandfield (Hoboken: Wiley, 2014), pp. 529-535.

8. G. Tarcy and A. Tabereaux, Light Metals 2011, ed. S. Lindsay (Hoboken: Wiley, 2011), pp. 329-332.

9. International Aluminium Institute, Workshop on PFC Emissions in the Aluminium Industry (London, UK, 2015).

10. X. Chen, W. Li, S. Qiu, Y. Zhang, and C. Bayliss, Light Metals 2013, ed. B. Sadler (Hoboken: Wiley, 2013), pp. 877881.

11. H. Asheim, T.A. Aarhaug, E. Sandnes, O.S. Kjos, A. Solheim, and G.M. Haarberg, ECS Trans. 69, 1 (2015).

12. A. Jassim, S. Ahkmetov, B.J. Welch, M. Skyllas-Kazacos, J. Bao, and Y. Yao, Light Metals 2015, ed. M. Hyland (Hoboken: Wiley, 2015), pp. 545-550.

13. H. Asheim, T.A. Aarhaug, A. Ferber, O.S. Kjos, G.M. Haarberg, 7th Kyoto International Forum for Environment and Energy (Kyoto, 2014).

14. B.J. Welch (Paper presented at the 10th Australasian Aluminium Smelting Technology Conference and Workshops, Launceston, Tasmania, 2011).

15. W. Li, Q. Zhao, J. Yang, S. Qiu, X. Chen, J. Marks, and C. Bayliss, Light Metals 2011, ed. S. Lindsay (Hoboken: Wiley, 2011), pp. 309-314.

16. D. Wong and J. Marks, Light Metals 2013, ed. B. Sadler (Hoboken: Wiley, 2013), pp. 865-870.

17. A.A. Zarouni, M. Reverdy, A. Zarouni, and K.G. Vankatasubramaniam, Light Metals 2013, ed. B. Sadler (Hoboken: Wiley, 2013), pp. 859-863.

18. N.R. Dando, N. Menegazzo, L. Espinoza-Nava, N. Westendorf, and E. Batista, Light Metals 2015, ed. M. Hyland (Hoboken: Wiley, 2015), pp. 551-555.

19. E. Batista, N.R. Dando, N. Menegazzo, and L. Espinoza-Nava, Light Metals 2016, ed. E. Williams (Hoboken: Wiley, 2016), pp. 545-550.

20. L. Dion, L.I. Kiss, S. Poncsák, and C. Lagacé, Light Metals 2016, ed. E. Williams (Hoboken: Wiley, 2016), pp. 545-550.

21. L. Dion, L.I. Kiss, C. Lagacé, R. Victor, and J.W. Evans, Light Metals 2015, ed. M. Hyland (Hoboken: Wiley, 2015), pp. 723-728.

22. A. Saltelli, M. Ratto, T. Andres, F. Campolongo, J. Cariboni, D. Gatelli, M. Saisana, and S. Tarantola, Global Sensitivity Analysis: The Primer, 1st ed. (Chischester: Wiley, 2008), pp. 53-108. 